\title{
Contrasting photosynthesis, photoinhibition and oxidative damage in honeysuckle (Lonicera japonica Thunb.) under iso-osmotic salt and drought stresses
}

\author{
Wenjun He ${ }^{\mathrm{a}, \mathrm{b}}$, Kun Yan ${ }^{\mathrm{a} * *}$, Yue Zhang ${ }^{\mathrm{c}}$, Lanxing Bian ${ }^{\mathrm{a}, \mathrm{d}}$, Huimin Mei ${ }^{\mathrm{e}}$, Guangxuan Han ${ }^{\mathrm{a} *}$ \\ ${ }^{a}$ CAS Key Laboratory of Coastal Environmental Processes and Ecological Remediation, Yantai Institute of Coastal Zone Research (YIC), Chinese Academy of Sciences \\ (CAS), Shandong Key Laboratory of Coastal Environmental Processes, YICCAS, Yantai, 264003, China \\ ${ }^{\mathrm{b}}$ University of Chinese Academy of Sciences, Beijing, 100049, China \\ ${ }^{\mathrm{c}}$ Agricultural and Rural Bureau of Sishui County, Jining, 273200, China \\ ${ }^{\mathrm{d}}$ College of Life Sciences, Yantai University, Yantai, 264005, China \\ e College of Life Sciences, Liaoning University, Shenyang, 264005, China
}

\section{A R T I C L E I N F O}

\section{Keywords:}

Lipid peroxidation

Photosynthetic electron transport

Photosystems interaction

Western blotting

\begin{abstract}
A B S T R A C T
Honeysuckle (Lonicera japonica Thunb.) is a traditional Chinese medicinal crop and belongs to the glycophyte with certain salt tolerance. This study aimed to deeply dissect its salt adaptability by contrasting photosynthesis, photoinhibition and oxidative damage under moderate and severe iso-osmotic salt (150 and $300 \mathrm{mM} \mathrm{NaCl})$ and drought (19.3\% and $28 \%$ PEG-6000) stresses with hydroponic protocol. Photosynthesis was more susceptible to drought stress than iso-osmotic salt stress in honeysuckle according to drought-induced greater decrease in photosynthetic rate. In contrast to salt-induced mild PSII and PSI photoinhibition, severe photosystem II (PSII) and photosystem I (PSI) photoinhibition arose upon iso-osmotic drought stress, indicated by greater decreased the maximal photochemical efficiency of PSII and PSI and remarkable loss of their reaction center proteins. However, PSII and PSI interaction hardly contributed to salt stability of photosynthetic apparatus because of saltinduced finite restriction on electron flow from PSII to PSI. Consistent with photosystems photoinhibition, leaf lipid peroxidation, $\mathrm{H}_{2} \mathrm{O}_{2}$ production and electrolyte leakage were elevated much greater by drought stress than iso-osmotic salt stress, confirming drought-induced severe oxidative stress in honeysuckle. Furthermore, the principal components analysis comprehensively showed higher salt adaptability in honeysuckle due to larger cluster separation upon drought stress than iso-osmotic salt stress. As an apparent reason, honeysuckle could prevent drought-induced tremendous leaf water loss upon iso-osmotic salt stress, and had a capacity to dispose accumulated $\mathrm{Na}^{+}$. Therefore, honeysuckle resembles halophytes in this respect and seems appropriate for planting in coastal saline land.
\end{abstract}

\section{Introduction}

The problems of soil drought and salinization may become serious in the future due to regional water scarcity and unbalanced precipitation particularly in arid regions and coastal zone under the background of global change (Hussain et al., 2015; Han et al., 2018). Soil drought and salinization are two kinds of major environmental stresses and have detrimental effects on crop growth and yield. Similar to drought stress, salt stress also disrupts water homostasis in plant tissues by inducing osmotic pressure, and some drought-induced physiological symptoms such as lowered transpiration and stomatal closure exists in plants exposed to salt stress as well (Zhu, 2002; Munns and Tester, 2008; Zhu, 2016). Besides osmotic pressure, plants have to confront ionic toxicity under salt stress, and $\mathrm{Na}^{+}$is the dominant toxic ingredient (Zhu, 2003; Munns and Tester, 2008; Turkan and Demiral, 2009). Salt-induced ionic toxicity usually does not arise as rapidly as osmotic stress, but may lead to severe inhibition on physiological metabolisms (Munns, 2002; Allakhverdiev and Murata, 2008; Yang et al., 2014). Accordingly, some studies proved that salt stress was more hazardous to plant growth than iso-osmotic drought stress (Muranaka et al., 2002; Cha-um and Kirdmanee, 2010; Cha-um et al., 2010; Patade et al., 2011; Hossain et al., 2017). In contrary, some plant species exhibited greater susceptibility to

\footnotetext{
* Corresponding authors at: Yantai Institute of Coastal Zone Research, Chinese Academy of Sciences, Chunhui road 17, Yantai, 264003, China.

E-mail addresses: yankunacademic@163.com, kyan@yic.ac.cn (K. Yan), gxhan@yic.ac.cn (G. Han).
} 
iso-osmotic drought stress rather than salt stress, indicating that salt stress may be not identical to a simple combination of osmotic stress and ionic toxicity (Zhao and Harris, 1992; Zhao et al., 2003; Hassine and Lutts, 2010; Silva et al., 2010; Sucre and Suárez, 2011; Amjad et al., 2015; Lan et al., 2020; Katuwal et al., 2020).

Salt and drought stresses can influence redox equilibrium and bring about secondary oxidative stress with excess generation of reactive oxygen species (ROS) in plant cells (Gill and Tuteja, 2010; Hossain and Dietz, 2016; van Zelm et al., 2020). As a consequence, oxidative damages on biological macromolecules such as lipids and proteins will further interfere with cellular functions and seriously depress plant growth. Consistently, oxidative damage was often noted in line with declined plant growth under salt and drought stresses. In photosynthetic organisms, the major ROS generation sites are located at photosystem I and II (PSI and PSII) in chloroplast, and oxidative stress bears close relation with photoinhibition and photosynthesis (Asada, 2006; Gill and Tuteja, 2010). As a fundamental metabolism for plant survival and growth, photosynthesis is sensitive to drought and salt stresses, and plant tolerance can be evaluated by photosynthetic analysis. It has been well documented that both salt and drought stresses initially cause stomatal limitation on photosynthesis, as plants can rapidly perceive elevated osmotic pressure, and the inhibition on dark enzymatic processes can further reduce $\mathrm{CO}_{2}$ fixation (Flexas and Medrano, 2002; Loreto et al., 2003; Yang et al., 2008; Chaves et al., 2009). Consequently, excitation pressure in chloroplast may be elevated to induce photosystems photoinhibition with excess ROS generation (Murata et al., 2007; Takahashi and Murata, 2008; Sonoike, 2011; Kalaji et al., 2018a). Photosystems photoinhibition which originates from oxidative damages on photosynthetic membrane proteins or lipids has bigger threat than stomatal limitation on photosynthesis, as the damaged photosystems cannot recover as readily as stomatal opening after the cease of stress. At present, $\mathrm{CO}_{2}$ assimilation and PSI photoinhibition have been analyzed by detecting gas exchange and the maximal photochemical efficiency of PSII (Fv/Fm) in some studies to discern plant tolerance to iso-osmotic salt and drought stresses (Muranaka et al., 2002; Cha-um and Kirdmanee, 2010; Cha-um et al., 2010). However, oxidative stress was rarely concerned in these studies, and it is still unclear how PSII donor and acceptor sides respond to iso-osmotic salt and drought stresses, as PSII performance cannot be comprehensively reflected by Fv/Fm (Li et al., 2009a; Yan et al., 2018a,b).

To date, less attention has been paid to PSI under salt and drought stresses, much less the comparison of its performance under iso-osmotic salt and drought stresses. In our recent studies, PSI was proved to be a crucial photoinhibition site in susceptible plant species or cultivars under salt stress (Yan et al., 2015a,b; Yan et al., 2020). In contrast, PSI inactivation was only reported in some trees with tremendous leaf water deficit after long severe drought stress (Huang et al., 2013; Zhang et al., 2016). Compared with PSII, the damaged PSI is difficult to be repaired, and PSI photoinhibition can aggravate PSII photoinhibition by elevating PSII excitation pressure through feedback inhibition on electron transport. Inversely, PSII photoinhibition can reduce ROS generation at PSI acceptor side by restricting electron donation to PSI and then decline the possibility of PSI photoinhibition. Thus, PSI photoinhibition is more harmful than PSII photoinhibition, and PSII and PSI coordination is critical for protecting PSI and even the whole photosynthetic apparatus. However, it is still largely unknown the role of PSII and PSI interaction in differentiating plant tolerance to iso-osmotic salt and drought stresses.

Honeysuckle (Lonicera japonica Thunb.) is a traditional medicinal crop in China and has strong adaptability to adverse environmental conditions such as low temperature, drought and barren soil. Drought tolerance of honeysuckle has been elucidated in terms of photosynthesis, osmolytes and leaf morphology and anatomy (Li et al., 2009b). In our recent study, the stability of photosynthesis and photosystems was maintained without oxidative stress by restricting leaf $\mathrm{Na}^{+}$accumulation in honeysuckle under salt stress (Yan et al., 2015a). Moreover, honeysuckle was demonstrated as an ideal economic crop for utilizing coastal saline land because of its salt adaptability and economic value according to our field experiments (Yan et al., 2016a, b; Yan et al., 2017). Plant salt tolerance can be deeply dissected by contrasting the effects of iso-osmotic salt and drought stress, as salt sensitive glycophytes commonly exhibit more vulnerability to iso-osmotic salt stress in contrary to the halophytes (Zhao et al., 2003; Hassine and Lutts, 2010; Patade et al., 2011; Sucre and Suárez, 2011; Hossain et al., 2017). However, there is no report about the effects of iso-osmotic salt and drought stresses on honeysuckle, a salt-tolerant glycophyte.

In this study, we intended to contrast photosynthesis, photoinhibition and oxidative stress in honeysuckle under moderate and severe iso-osmotic salt and drought stresses for deeply disclosing its salt adaptability. As a glycophyte, honeysuckle more likely has stronger adaptability to drought stress than iso-osmotic salt stress. Our study can enrich the understanding of salt tolerance mechanism in glycophyte and provide a reference for honeysuckle cultivation in coastal saline land.

\section{Materials and methods}

\subsection{Plant growth and treatments}

Bare-rooted honeysuckle (Lonicera japonica Thunb.) plants were bought from Jiujianpeng Agricultural Technology Limited Company (Pingyi, Shangdong, China). These plants are one-year old and belong to widely cultivated variety named Beihuayihao. Honeysuckle plants were planted in plastic boxes ( 9 plants per tank) containing Hoagland nutrient solution (pH 5.7) and placed in artificial chambers (Qiushi, China). The Hoagland nutrient solution contains $\mathrm{KNO}_{3}\left(255 \mathrm{mg} \mathrm{L}^{-1}\right), \mathrm{KH}_{2} \mathrm{PO}_{4}$ $\left(67.5 \mathrm{mg} \mathrm{L}^{-1}\right), \mathrm{NH}_{4} \mathrm{NO}_{3}\left(40 \mathrm{mg} \mathrm{L}^{-1}\right), \mathrm{MgSO}_{4} \cdot 7 \mathrm{H}_{2} \mathrm{O}\left(245 \mathrm{mg} \mathrm{L}^{-1}\right)$, Ca $\left(\mathrm{NO}_{3}\right)_{2} \cdot 4 \mathrm{H}_{2} \mathrm{O} \quad\left(590 \mathrm{mg} \mathrm{L}^{-1}\right), \quad \mathrm{MnCl}_{2} \cdot 4 \mathrm{H}_{2} \mathrm{O} \quad\left(905 \mu \mathrm{g} \mathrm{L}^{-1}\right), \quad \mathrm{H}_{3} \mathrm{BO}_{3}$ $\left(1.43 \mathrm{mg} \mathrm{L}^{-1}\right), \mathrm{ZnSO}_{4} \cdot 7 \mathrm{H}_{2} \mathrm{O}\left(0.11 \mathrm{mg} \mathrm{L}^{-1}\right), \mathrm{CuSO}_{4} \cdot 5 \mathrm{H}_{2} \mathrm{O}\left(0.04 \mathrm{mg} \mathrm{L}^{-1}\right)$, $\mathrm{MoNa}_{2} \mathrm{O}_{4} \quad\left(60.5 \mu \mathrm{g} \mathrm{L}^{-1}\right), \quad \mathrm{FeSO}_{4} \cdot 7 \mathrm{H}_{2} \mathrm{O} \quad\left(18.63 \mathrm{mg} \mathrm{L}^{-1}\right) \quad$ and $\mathrm{C}_{10} \mathrm{H}_{14} \mathrm{~N}_{2} \mathrm{Na}_{2} \mathrm{O}_{8} \cdot 2 \mathrm{H}_{2} \mathrm{O}\left(13.93 \mathrm{mg} \mathrm{L}^{-1}\right)$. The Hoagland nutrient solution was continuously aerated and refreshed every two days. In the chambers, day/night temperature, humidity and photon flux density were set at $25 / 18^{\circ} \mathrm{C}, 70 \%$ and $400 \mu \mathrm{molm}^{-2} \mathrm{~s}^{-1}$ (12 h per day from 07:00 to 19:00). After 35 days, healthy and uniform plants were selected for isoosmotic salt and drought treatments. $\mathrm{NaCl}$ and polyethylene glycol 6000 (PEG-6000) were used to conduct salt and drought treatments. Water potentials in nutrient solutions with 150 and $300 \mathrm{mM} \mathrm{NaCl}$ were $-0.68 \mathrm{MPa}$ and-1.28 MPa, and equal to those in $19.3 \%$ and $28 \%$ PEG$6000(\mathrm{~m} / \mathrm{v})$ solutions. $\mathrm{NaCl}$ was added to nutrient solution incrementally by $50 \mathrm{mM}$ step every day to the final concentrations at 150 and $300 \mathrm{mM}$ for avoiding osmotic shock, and correspondingly, PEG was incrementally added to nutrient solution every day to the final concentrations at $19.3 \%$ and $28 \%$. During the period, the water potential of nutrient solution with $\mathrm{NaCl}$ addition was measured every day to determine the daily added quantity of PEG-6000 for controlling the equal water potential throughout. Nutrient solution without PEG and $\mathrm{NaCl}$ was used for cultivating control plants. The newly expanded leaves were sampled from four replicate plants (one plant from one box) in each treatment for measuring the following parameters. Gas exchange and modulated chlorophyll fluorescence parameters were continuously measured at day 0, 1, 4 and 6 under severe iso-osmotic drought and salt stress at day $0,3,10,15$ and 20 under moderate iso-osmotic drought and salt stress. Other measurements were done after $6 \mathrm{~d}$ and $20 \mathrm{~d}$ of severe and moderate iso-osmotic drought and salt stress, respectively.

\subsection{Measurements of $\mathrm{Na}^{+}$and relative water content}

According to Song et al. (2011), dried leaf powder (0.1 g) was boiled with deionized $\mathrm{H}_{2} \mathrm{O}(25 \mathrm{~mL})$ for $2 \mathrm{~h}$, and the supernatant was collected for measuring $\mathrm{Na}^{+}$content by using an atomic absorption spectrophotometer (TAS-990, Beijing, China).

Fresh leaves were harvested and weighed (fresh weight, FW), and 
then were immersed in distilled water for $4 \mathrm{~h}$ at room temperature to determine saturated fresh weight (SW). At last, the leaves were dried completely in an oven at $70^{\circ} \mathrm{C}$ and weighed (dry weight, DW). Relative water content $(\mathrm{RWC})$ was calculated as: $\mathrm{RWC}=(\mathrm{FW}-\mathrm{DW}) /(\mathrm{SW}-\mathrm{DW})$ $\times 100 \%$.

\subsection{Measurements of $\mathrm{MDA}$ and $\mathrm{H}_{2} \mathrm{O}_{2}$ contents}

Leaf tissues $(0.2 \mathrm{~g})$ were ground under liquid nitrogen and homogenized in $4 \mathrm{ml} 0.1 \%$ TCA. The homogenate was centrifuged at $12,000 \times$ $g$ and $4{ }^{\circ} \mathrm{C}$ for $10 \mathrm{~min}$ to collect the supernatant for measurements of MDA and $\mathrm{H}_{2} \mathrm{O}_{2}$ contents. MDA content was determined by thiobarbituric acid reaction to reflect the extent of lipid peroxidation (Yan et al., 2020). The supernatant $(1 \mathrm{ml})$ was mixed with $0.1 \mathrm{mM}$ potassium phosphate buffer ( $1 \mathrm{ml}, \mathrm{pH} 7.0)$ and $1 \mathrm{mM} \mathrm{KI}(2 \mathrm{ml})$, and the absorbance at $390 \mathrm{~nm}$ was recorded for calculating $\mathrm{H}_{2} \mathrm{O}_{2}$ content (Yan et al., 2020).

\subsection{Histochemical detection of $\mathrm{H}_{2} \mathrm{O}_{2}$ and leaf electrical conductivity}

For histochemical detection of $\mathrm{H}_{2} \mathrm{O}_{2}$, leaf samples were vacuum infiltration in 3,3-diaminobenzidine (DAB) solution $\left(0.1 \mathrm{mg} \mathrm{ml}^{-1}\right.$ in $50 \mathrm{mM}$ Tris-acetic acid; $\mathrm{pH} 3.8$ ) for $3 \mathrm{~min}$ and incubated at room temperature for $24 \mathrm{~h}$ in the dark. Leaf samples were washed three times with distilled water. Thereafter, the leaves were decolorized by immersion in boiling ethanol (85 \%) for $15 \mathrm{~min}$ and photographed (Yan et al., 2020).

Fresh leaf discs ( $1 \mathrm{~cm}$ diameter) were punched out and placed in a test tube containing $20 \mathrm{ml}$ distilled deionized water. The leaf samples were vacuum infiltrated for $10 \mathrm{~min}$ and then rotary shaken for $3 \mathrm{~h}$. The initial electrical conductivity of the solution (S1) was measured by using a conductivity meter (DDBJ-350 F, Shanghai, China). Then, the samples were boiled at $95^{\circ} \mathrm{C}$ for $30 \mathrm{~min}$ to release all electrolytes. After cooling at room temperature, the final electric conductivity (S2) was measured. The electrolyte leakage was calculated as: EL $(\%)=(\mathrm{S} 1 / \mathrm{S} 2) \times 100 \%$.

\subsection{Measurements of gas exchange and modulated chlorophyll} fluorescence

Gas exchange and modulated chlorophyll fluorescence were simultaneously measured by using an open photosynthetic system (LI6400XTR, Li-Cor, Lincoln, NE, USA) equipped with a fluorescence leaf chamber (6400-40 LCF, Li-Cor). All parameters were measured with $800 \mu \mathrm{mol} \mathrm{m}^{-2} \mathrm{~s}^{-1}$ light intensity. Temperature and $\mathrm{CO}_{2}$ concentration were set at $25^{\circ} \mathrm{C}$ and $400 \mu \mathrm{mol} \mathrm{mol}^{-1}$ in the leaf cuvette. Net photosynthesis rate $(P n)$, stomatal conductance $(G s)$, intracellular $\mathrm{CO}_{2}$ concentration $(\mathrm{Ci})$ and transpiration rate (Tr) were simultaneously noted. In addition, steady-state fluorescence yield was also recorded, and a saturating actinic light pulse of $8000 \mu \mathrm{mol} \mathrm{m}^{-2} \mathrm{~s}^{-1}$ for $0.7 \mathrm{~s}$ was used to produce maximum fluorescence yield by temporarily inhibiting PSII photochemistry. Subsequently, the minimum fluorescence in the steady state was detected during a brief interruption of actinic light irradiation in the presence of far-red light. Photochemical efficiency of PSII (ФPSII) and PSII excitation pressure (1-qP) were calculated by using these parameters (Maxwell and Johnson, 2000; Yan et al., 2018a).

\subsection{Measurements of chlorophyll fluorescence and modulated $820 \mathrm{~nm}$ reflection transients}

Chlorophyll fluorescence and modulated $820 \mathrm{~nm}$ reflection transients were analyzed with a multifunctional plant efficiency analyzer (MPEA, Hansatech, Norfolk, UK), and the instrument has been described in detail (Strasser et al., 2010; Kalaji et al., 2012, 2018b). The leaves were adapted in dark for $30 \mathrm{~min}$ before the measurement. Thereafter, the leaves were orderly illuminated with $1 \mathrm{~s}$ red light $(627 \mathrm{~nm}$, $5000 \mu \mathrm{mol}$ photons $\left.\mathrm{m}^{-2} \mathrm{~s}^{-1}\right)$, $10 \mathrm{~s}$ far red light $(735 \mathrm{~nm}, 200 \mu \mathrm{mol}$ photons $\mathrm{m}^{-2} \mathrm{~s}^{-1}$ ) and $2 \mathrm{~s}$ red light $\left(627 \mathrm{~nm}, 5000 \mu \mathrm{mol}\right.$ photons $\mathrm{m}^{-2} \mathrm{~s}^{-1}$ ) (Strasser et al., 2010; Dabrowski et al., 2016). Chlorophyll fluorescence and modulated $820 \mathrm{~nm}$ reflection were simultaneously recorded during the illumination. Monitoring modulated reflection change near $820 \mathrm{~nm}$ is a very convenient way to follow redox state of PSI. Relative value of the maximal difference of $820 \mathrm{~nm}$ reflection during the last $2 \mathrm{~s}$ red illumination was used to indicate the maximal photochemical efficiency of PSI ( $\Delta$ MR/MR $)$ (Schansker et al., 2003; Yan et al., 2013). $\mathrm{MR}_{0}$ is the value of $820 \mathrm{~nm}$ reflection at $0.7 \mathrm{~ms}$ (the first reliable MR measurement). $\Delta \mathrm{MR}$ is the value of the maximal difference of $820 \mathrm{~nm}$ reflection at the last $2 \mathrm{~s}$ red light illumination. Chlorophyll fluorescence transients were quantified by JIP test to calculate the following parameters according to previous studies (Strasser et al., 2010), Fv/Fm, total performance index (PItotal), PSII performance index (PIabs), ratio of relative variable fluorescence at $\mathrm{K}$ step to that at $\mathrm{J}$ step $\left(\mathrm{W}_{\mathrm{k}}\right)$, primary quinone $\left(\mathrm{Q}_{\mathrm{A}}\right)$ reducing reaction centers per PSII antenna chlorophyll (RC/ABS) and probability with which an electron moves beyond $\mathrm{Q}_{\mathrm{A}}$ (ETo/TRo) and from the intersystem electron carriers to reduce PSI end electron acceptors (REo/ETo).

\subsection{Isolation of thylakoid membranes and western blot}

According to the method of Yan et al. (2018a), leaf discs (4 g) were ground under liquid nitrogen and homogenized in $400 \mathrm{mM}$ sucrose, $50 \mathrm{mM}$ HEPES-KOH (pH 7.8), $10 \mathrm{mM} \mathrm{NaCl}$, and $2 \mathrm{mM} \mathrm{MgCl}_{2}$. The homogenate was filtered through two layers of cheesecloth and then centrifuged at $5000 \mathrm{~g}$ and $4{ }^{\circ} \mathrm{C}$ for $10 \mathrm{~min}$ for collecting thylakoid pellets. At last, the pellets were resuspended in the homogenization buffer. The homogenate $(20 \mu \mathrm{L})$ was mixed with $96 \%$ ethanol $(2.98 \mathrm{~mL})$ and then centrifuged at $14,000 \mathrm{~g}$ and $4{ }^{\circ} \mathrm{C}$ for $1 \mathrm{~min}$. Liquid supernatant was used to measure the absorbance at 649 and $665 \mathrm{~nm}$ for calculating chlorophyll content (Yan et al., 2018b).

Thylakoid membranes containing $10 \mu \mathrm{g}$ chlorophyll were separated by a $12 \%(w / w)$ SDS-PAGE gel. Proteins from the gel were transferred onto polyvinylidene fluoride membrane by semi dry method. After blocking with $5 \%$ skimmed milk for $1 \mathrm{~h}$, the membrane was incubated for $2 \mathrm{~h}$ with the primary anti-PsbA and anti-PsaA antibodies (PhytoAB, USA), respectively and then incubated with horseradish peroxidase conjugated anti-rabbit IgG antibody (PhytoAB, USA) for $2 \mathrm{~h}$. The BeyoECL Plus substrate (Beyotime Biotechnology, China) was applied to test immunoreaction, and the chemiluminescence was recorded by using a Tanon-5500 cooled CCD camera (Tanon, Shanghai, China).

\subsection{Statistical analysis}

One-way ANOVAs Two-way ANOVAs were carried out by using SPSS 17.0 (SPSS Inc., Chicago, IL, USA) to examine the effects of treatment time, treatment patterns and their interactions on photosynthetic and fluorescence parameters. The values presented are the mean of samples collected from four replicate plants. The comparisons of means were determined using a least significant difference test, and the differences were considered significant at $P<0.05$.

Principal component analysis (PCA) was performed to show the integrated responses of honeysuckle to iso-osmotic drought and salt stresses. Beforehand, KMO and Bartlett's spherical tests were conducted by using SPSS 17.0 to examine data correlation for determining the feasibility of PCA. In this study, KMO value of the data reached 0.81 $(\mathrm{KMO}>0.6)$, and the data also passed Bartlett's spherical test $(P<$ 0.01). Then, PCA was performed and graphed by using Canoco 4.5.

\section{Results}

\subsection{Gas exchange, PSII actual quantum yield and excitation pressure}

$P n, G s, T r$ and $\Phi$ PSII tremendously decreased after 1 day of severe salt and drought stresses, and the decrease persisted until day 6 (Fig. 1A, C, G, I). Significant decrease in $P n, G s, T r$ and $\Phi P S I I$ was also found under moderate drought and salt stresses (Fig. 1B, D, H, J). Pn, Gs, Tr and ФPSII 


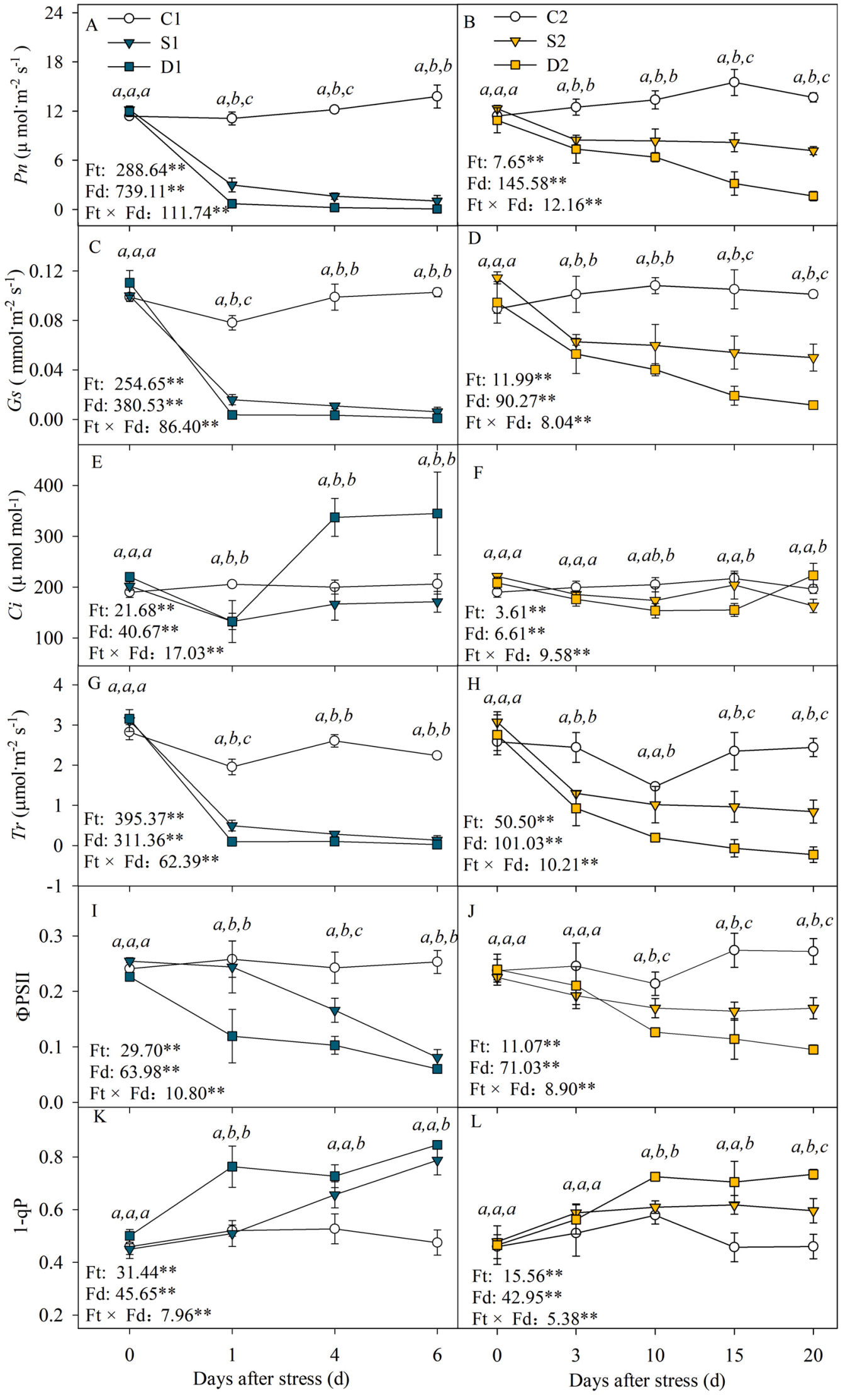

Fig. 1. Changes in photosynthetic rate (Pn, A, B), stomatal conductance ( $G s, \mathrm{C}$, D) and intercellular $\mathrm{CO}_{2}$ concentration (Ci, E, F), transpiration ( $T r, \mathrm{G}, \mathrm{H})$, actual photochemical efficiency of PSII (ФPSII, I, J) and PSII excitation pressure (1-qP, $\mathrm{K}, \mathrm{L})$ in honeysuckle under iso-osmotic salt and drought stress. C1 and C2 indicate two groups of control plants without salt or drought stress. S1 and D1 indicate plants exposed to severe isoosmotic stresses with $300 \mathrm{mM} \mathrm{NaCl}$ and $28 \%$ PEG, respectively. S2 and D2 indicate plants exposed to moderate isoosmotic stresses with $150 \mathrm{mM} \mathrm{NaCl}$ and 19.3 \% PEG, respectively. Data in the figure indicate mean of four replicates $( \pm \mathrm{SD}$ ), and different letters on error bars indicate significant difference at $P<$ 0.05. Ft, Fd and $\mathrm{Ft} \times \mathrm{Fd}$, respectively, indicate treatment time effect, treatment pattern effect and interaction effect between treatment time and pattern. The effect at the significant level of 0.05 is indicated by *, and the effect at the significant level of 0.01 is indicated by $* *$. The symbols, Ft, Fd, Ft $\times$ Fd, C1, S1, D1, C2, S2 and D2, are also used in the following figures. 
were at a relatively higher level under iso-osmotic salt stress because of drought-induced greater decrease in them (Fig. 1A-D, G-J). $\mathrm{Ci}$ was declined initially but increased to a significant higher level after 4 days of severe drought stress, and similarly, the initial decrease in $\mathrm{Ci}$ was also reversed after 20 days of moderate drought stress (Fig. 1E, F). During iso-osmotic salt stress, only lowered $\mathrm{Ci}$ could be observed (Fig. 1E, F).
Severe and moderate drought stress significantly elevated 1-qP at day 1 and day 10 respectively, whereas the marked elevation of 1-qP occurred later and was less under iso-osmotic salt stress (Fig. 1K, L). Besides treatment pattern, treatment time also significantly influenced the above parameters, and there was a significant interactive effect between treatment pattern and treatment time (Fig. 1).

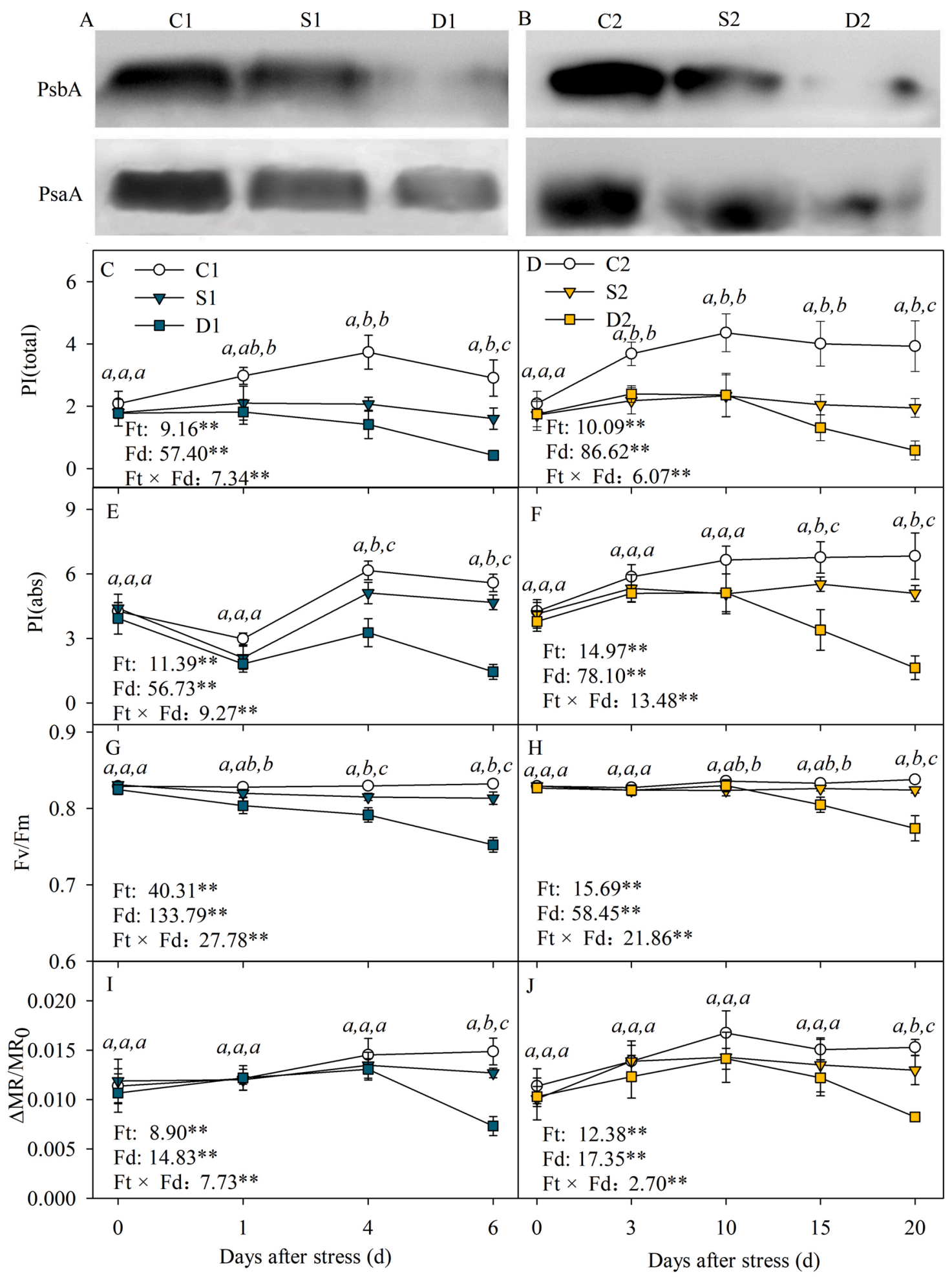

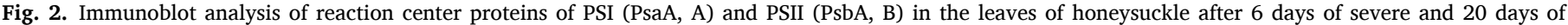

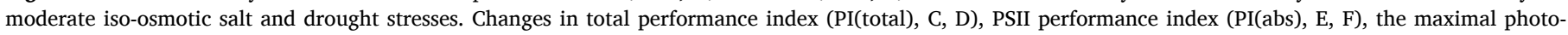

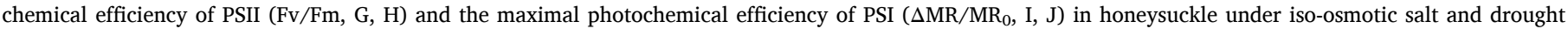
stresses. Data in the figure indicate mean of four replicates $( \pm \mathrm{SD})$, and different letters on error bars indicate significant difference at $P<0.05$. 


\subsection{Immunoblot analysis, total and PSII performance index and the maximal photochemical efficiency of PSII and PSI}

The abundance of PSI reaction center protein (PsaA) and PSII reaction center protein (PsbA) were obviously decreased after drought stress and slightly affected after iso-osmotic salt stress (Fig. 2A, B). Significant decline in PI(total) and PI(abs) occurred during both salt and drought stresses, and iso-osmotic drought stress caused greater decrease in them (Fig. 2C-F).

Fv/Fm was significantly decreased after 1 day of severe drought stress, and the decrease was up to $9.61 \%$ at day 6 (Fig.2G). Severe drought stress initially had no obvious effect on $\Delta M R / M_{0}$ and remarkably decreased it by $46.32 \%$ at day 6 (Fig. 2I). Under moderate drought stress, $\mathrm{Fv} / \mathrm{Fm}$ and $\Delta \mathrm{MR} / \mathrm{MR}_{0}$ were significantly decreased at day 15 , and the decrease reached $6.48 \%$ and $49.47 \%$ at day 20 (Fig. $2 \mathrm{H}$, $\mathrm{J})$. Moderate iso-osmotic salt stress also induced significant decrease in
$\mathrm{Fv} / \mathrm{Fm}$ and $\Delta \mathrm{MR} / \mathrm{MR}_{0}$, but the decrease was much less than those upon drought stress (Fig. $2 \mathrm{H}, \mathrm{J}$ ). Besides treatment pattern, treatment time also significantly influenced these parameters, and there was a significant interactive effect between treatment pattern and treatment time (Fig. 2C-J).

\subsection{Characterization of photosynthetic electron transport}

ETo/TRo was significantly decreased after 4 days of severe drought stress, while decreased $\mathrm{RC} / \mathrm{ABS}$ and increased $\mathrm{W}_{\mathrm{k}}$ became remarkable after 6 days of severe drought stress (Fig. 3A, E, G). After 15 days of moderate drought stress, remarkable decrease in ETo/TRo and RC/ABS occurred with significant increase in $\mathrm{W}_{\mathrm{k}}$, however, these parameters were not obviously affected by iso-osmotic salt stress (Fig. 3B, F, H). Inconsistently, REo/ETo was significantly declined after 1 day of severe salt stress and 3 days of moderate salt stress, and salt-induced decrease

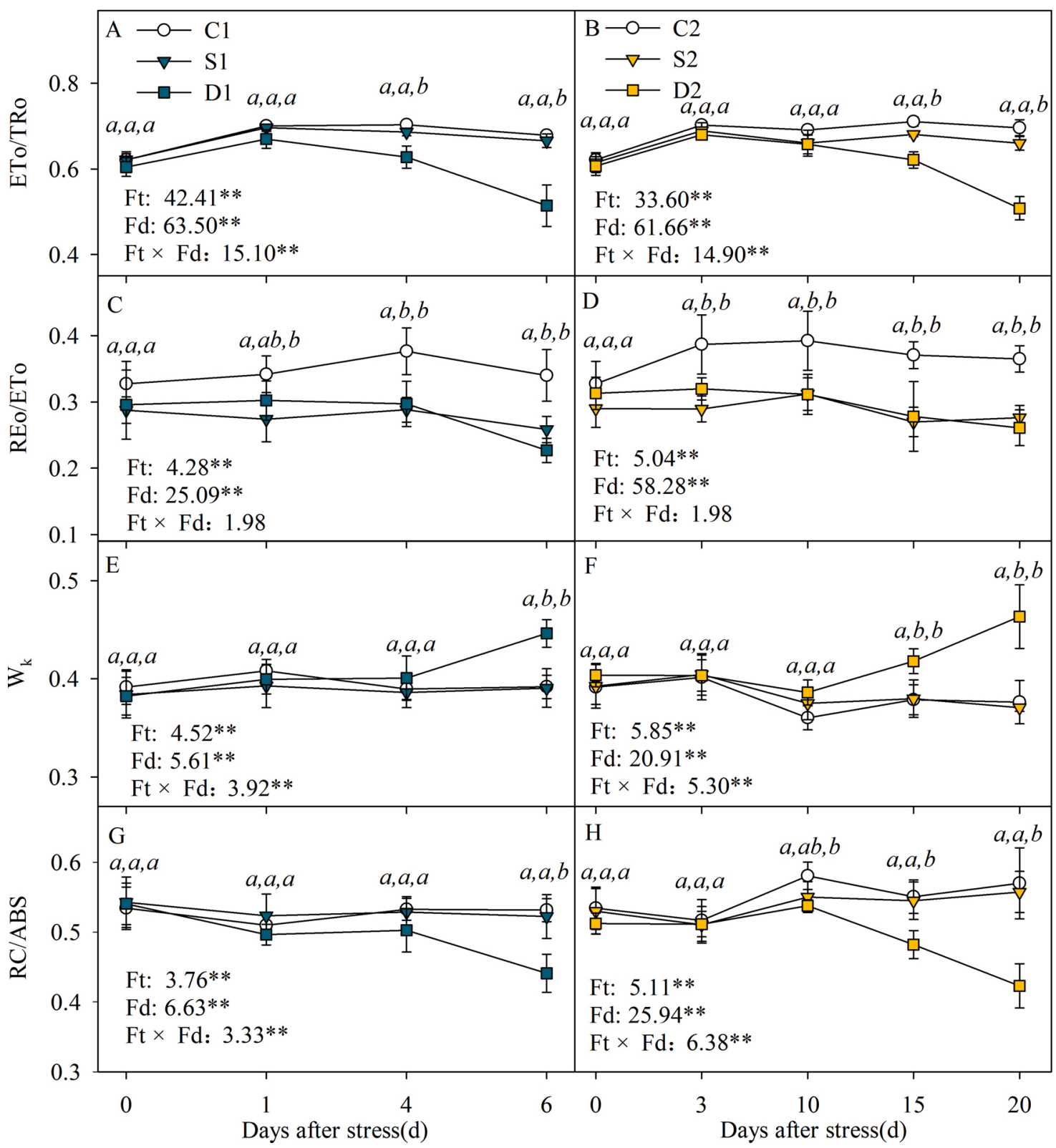

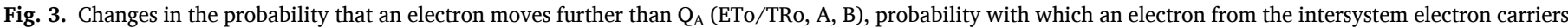

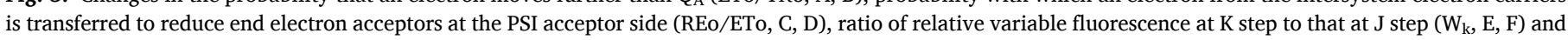

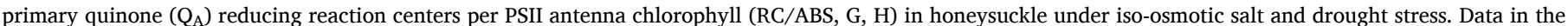
figure indicate mean of four replicates $( \pm \mathrm{SD})$, and different letters on error bars indicate significant difference at $P<0.05$. 
in REo/ETo was approximate to that upon iso-osmotic drought stress (Fig. 3C, D). Besides treatment pattern, treatment time also had significant effect on these parameters, and the significant interactive effect between treatment pattern and treatment time was also found apart from REo/ETo (Fig. 3).

\subsection{Chlorophyll a fluorescence and modulated $820 \mathrm{~nm}$ reflection transients}

$\mathrm{J}$ and I steps appear due to the accumulated reduced $\mathrm{Q}_{\mathrm{A}}$ and $\mathrm{PQ}$. After drought stress, $\mathrm{J}$ and I steps were significantly elevated, indicating that electron transport at PSII acceptor side beyond $\mathrm{Q}_{\mathrm{A}}$ and $\mathrm{PQ}$ were inhibited (Fig. 4A, C). The appearance of $\mathrm{K}$ step represents the injury on OEC at PSII donor side (Fig. 4A, C). After drought stress, elevated K step indicated that PSII donor side was impaired. In contrast, I step was obviously elevated under both drought and salt stresses (Fig. 4A, C).

MR signals are presented by $M R / M_{0}$, and the initial decrease in $820 \mathrm{~nm}$ reflection signal indicated PSI oxidation, and the subsequent increase suggested that PSI was gradually re-reduced. Both salt and drought stresses evidently restricted PSI oxidation, however, PSI rereduction was inhibited by drought stress rather than iso-osmotic salt stress (Fig. 4B, D).

\subsection{Lipid peroxidation, $\mathrm{H}_{2} \mathrm{O}_{2}$ content and electrolyte leakage}

Lipid peroxidation extent was indicated by malondialdehyde (MDA) content in plant tissue. Salt stress significantly increased leaf $\mathrm{H}_{2} \mathrm{O}_{2}$ content, lipid peroxidation and electrolyte leakage, and comparatively, greater increase appeared under iso-osmotic drought stress (Fig. 5C-H). Correspondingly, histochemical staining with 3,3-diaminobenzidine also suggested the greater leaf $\mathrm{H}_{2} \mathrm{O}_{2}$ generation under drought stress than iso-osmotic salt stress according to drought-induced intense brown colour in leaf discs (Fig. 5A, B).

\section{6. $\mathrm{Na}^{+}$content and relative water content}

Leaf $\mathrm{Na}^{+}$content was significantly elevated by $89.20 \%$ and $71.87 \%$ after severe and moderate salt stresses, but iso-osmotic drought stress had no significant effect on leaf $\mathrm{Na}^{+}$content (Fig. 6A, C). Leaf relative water content was markedly declined after salt and drought stresses, and the decrease by $46.64 \%$ and $23.88 \%$ upon severe and moderate drought stresses were greater than those under iso-osmotic salt stresses (Fig. 6B, D).

\subsection{Principal component analysis}

The first and second principal components (PCs), respectively, reflect $63.50 \%$ and $25.70 \%$ variation of the experimental data, and altogether explain $89.20 \%$ variation. Leaf $\mathrm{Na}^{+}$content majorly contribute to PC2 formation, and PC1 formation covers leaf water content, photosynthetic rate, oxidative parameters and photochemical indices, indicating a close relation of oxidative damage and photosynthesis with leaf water status rather than $\mathrm{Na}^{+}$content (Fig. 7). This finding conformed to the greater oxidative damage, photosynthetic depression and leaf water loss under drought stress than iso-osmotic salt stress. The samples distribution within PC1/PC2 plane is heterogeneous, and can be positioned into six separated clusters in accordance with six different treatments (Fig. 7). PC2 clearly separated salt-treated plants from control and droughttreated plants because of leaf $\mathrm{Na}^{+}$accumulation under salt stress (Fig. 7). In particular, PC1 obviously separated all clusters in the series

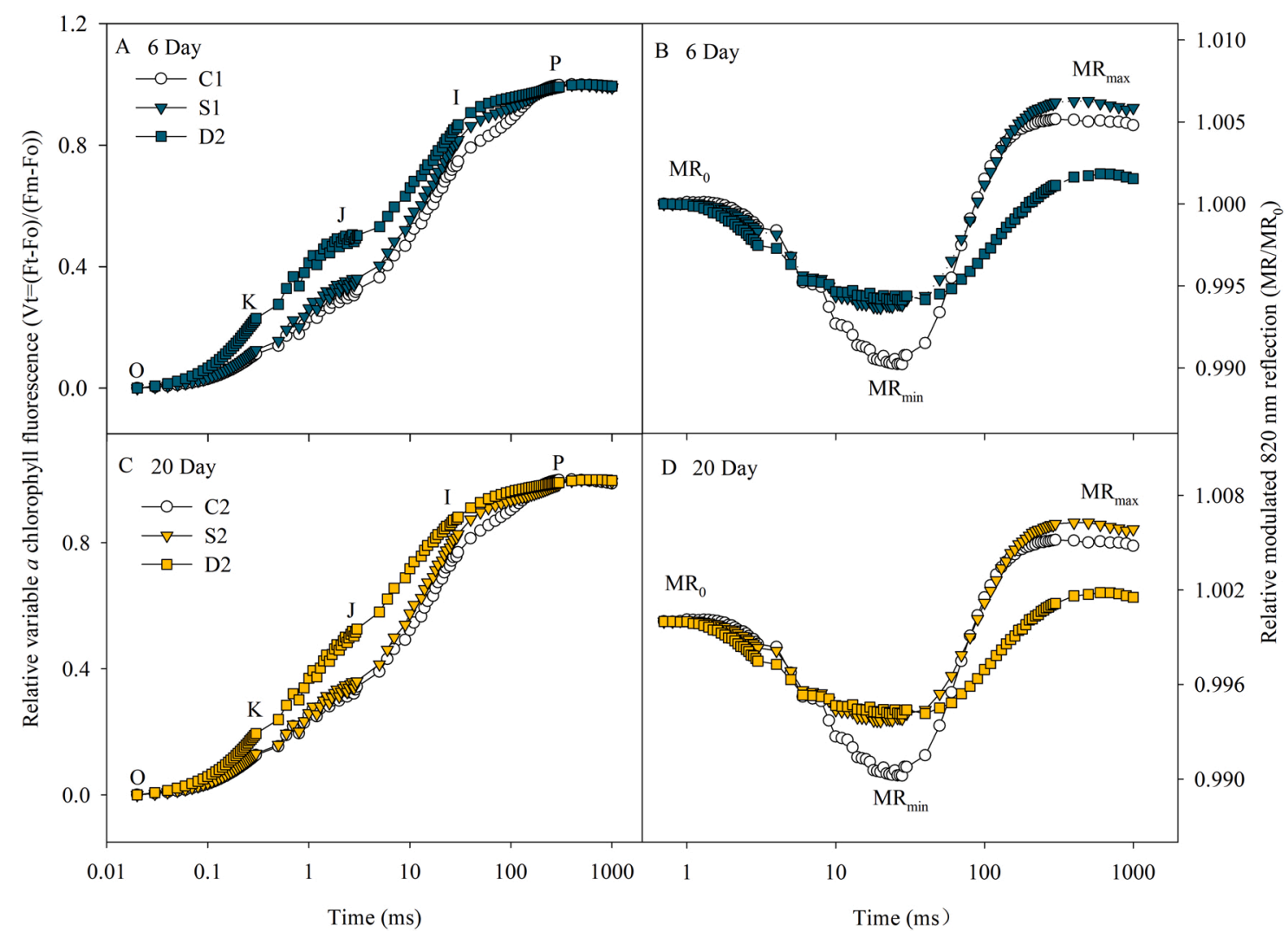

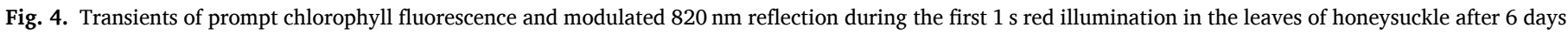

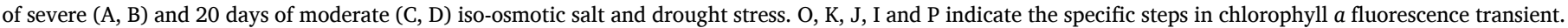

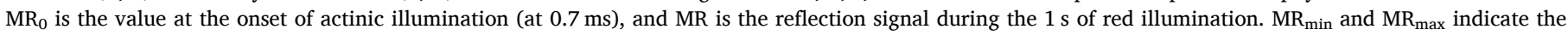

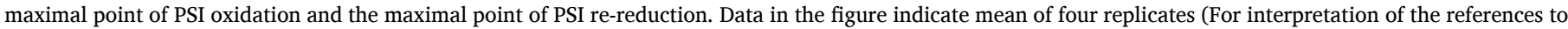
colour in this figure legend, the reader is referred to the web version of this article). 
A

$\mathrm{C} 1$

$\mathrm{S}$

D1

B

C2

S2
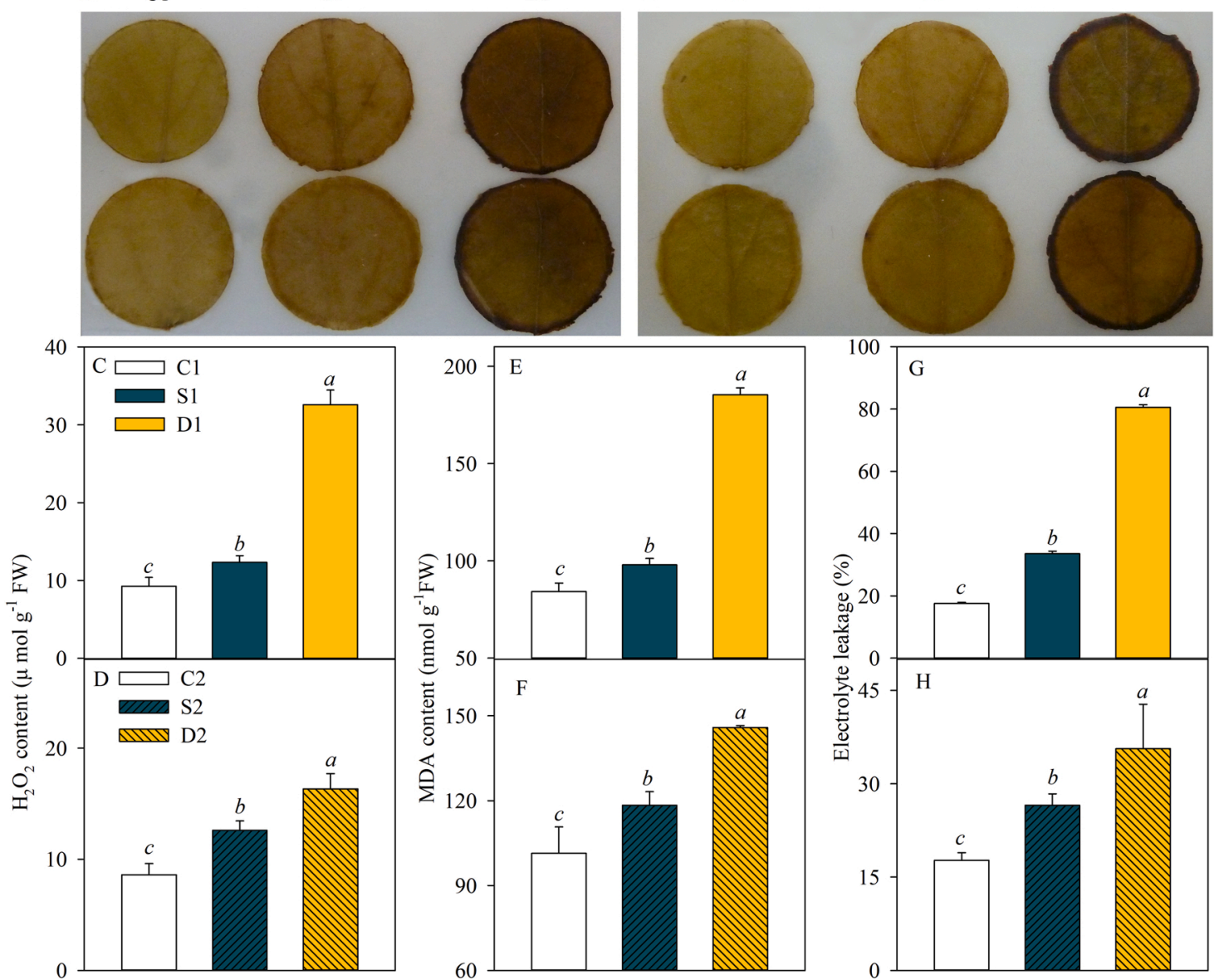

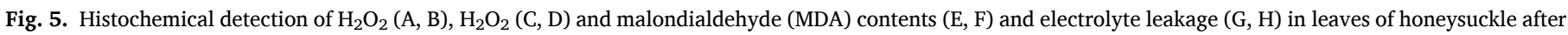

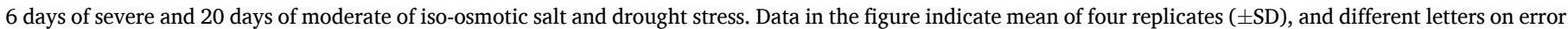
bars indicate significant difference at $P<0.05$.

of severe and moderate iso-osmotic salt and drought stresses, and drought-induced cluster separation from control plants was greater than the separation induced by iso-osmotic salt stress, suggesting that honeysuckle endured severe oxidative stress with more detrimental effects on photosynthesis and photosystems under drought stress (Fig. 7).

\section{Discussion}

Photosynthesis in honeysuckle exhibited more susceptibility under drought stress than iso-osmotic salt stress according to drought-induced greater decrease in $\mathrm{Pn}$. Stomatal closure serves as an important selfprotective way by reducing water loss from transpiration under osmotic pressure, however, as a side effect, this protective way inevitably blocks $\mathrm{CO}_{2}$ diffusion into leaf tissue and leads to stomatal limitation on photosynthesis (Chaves et al., 2009; Yan et al., 2018c). The concomitant decrease in $\mathrm{Pn}, \mathrm{Gs}, \mathrm{Ci}$ and $\mathrm{Tr}$ illuminated the positive and negative effects of stomatal closure in honeysuckle under salt stress (Fig. 1A-H). In contrast, drought-induced greater decrease in Gs, $T r$ and $P n$ suggested that honeysuckle encountered bigger osmotic pressure and had to further reduce water loss from transpiration with the sacrifice of $\mathrm{CO}_{2}$ assimilation (Fig. 1A-D, G-H). Actually, leaf water status was interfered more seriously in honeysuckle under iso-osmotic drought stress (Fig. 6B, D). Depressed $\mathrm{CO}_{2}$ assimilation can elevate excitation pressure in chloroplast, and threaten photosynthetic apparatus by elevating the possibility of ROS generation (Murata et al., 2007; Sonoike, 2011; Yan et al., 2020). Thus, higher PSII excitation pressure appeared with lower PSII electron transport in honeysuckle under drought stress than iso-osmotic salt stress, and could augment the risk of oxidative damage on photosynthetic apparatus (Fig. 1I-L). Notably, non-stomatal factors rather than stomatal limitation were mainly responsible for decreased $\mathrm{Pn}$ at later period of drought stress due to inverse variation of $\mathrm{Ci}$ and $\mathrm{Gs}$ (Fig. 1A-F), implying photosynthetic apparatus probably had been damaged.

PSII and PSI photoinhibition arose in honeysuckle exposed to drought stress, indicated by lowered $\mathrm{Fv} / \mathrm{Fm}$ and $\Delta \mathrm{MR} / \mathrm{MR}_{0}$, and decreased PI(total) corroborated drought-induced deleterious effects on photosynthetic apparatus (Fig. 2C-D, G-J). Particularly, large loss of PsaA and PsbA proteins confirmed severe PSII and PSI photoinhibition in honeysuckle after drought stress (Fig. 2A, B). Oppositely, iso-osmotic salt stress had smaller influence on photosynthetic apparatus and led to mild PSII and PSI photoinhibition and slight decrease in PsaA and PsbA abundance (Fig. 2A-B, G-J). In parallel with lowered Fv/Fm, drought stress reduced the amount of active PSII reaction centers and depressed electron generation from PSII donor side and electron transport at PSII acceptor side according to increased $\mathrm{W}_{\mathrm{k}}$ with elevated $\mathrm{K}$ step and decreased ETo/TRo with elevated J step respectively, and consequently, PSII entire performance was greatly declined by drought stress (Figs. 2C, D, 3 A, B, E, F and 4A, C). Recently, the large suppression on PSII photosynthetic activity has been reported in some salt-sensitive cultivars of glycophytes such as sweet sorghum and barley (Kalaji et al., 2018b; Rastogi et al., 2020). However, PSII entire performance and PSII components in honeysuckle showed greater tolerance to salt stress than iso-osmotic drought stress (Fig. 3). PSII was more vulnerable than PSI according to earlier decrease in $\mathrm{Fv} / \mathrm{Fm}$ than $\Delta \mathrm{MR} / \mathrm{MR}_{0}$ under severe drought stress (Fig. 2G, I), and rapid PSII photoinhibition restricted electron flow to PSI, and even led to PSII and PSI disconnection at day 6 

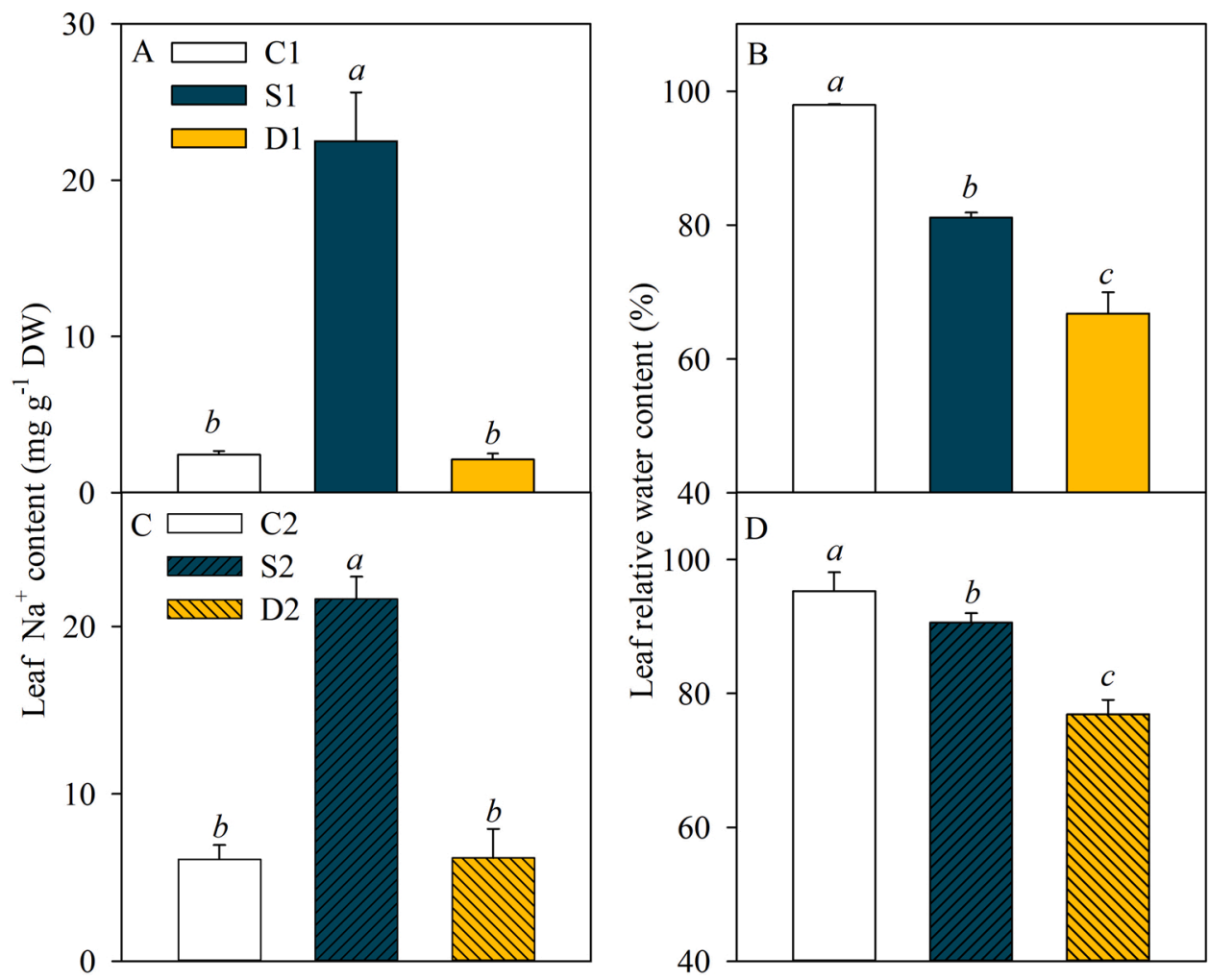

Fig. 6. Leaf $\mathrm{Na}^{+}$and relative water contents after 6 days of severe (A, B) and 20 days of moderate (C, D) iso-osmotic salt and drought stresses. Data in the figure indicate mean of four replicates $( \pm \mathrm{SD})$, and different letters on error bars indicate significant difference at $P<0.05$.

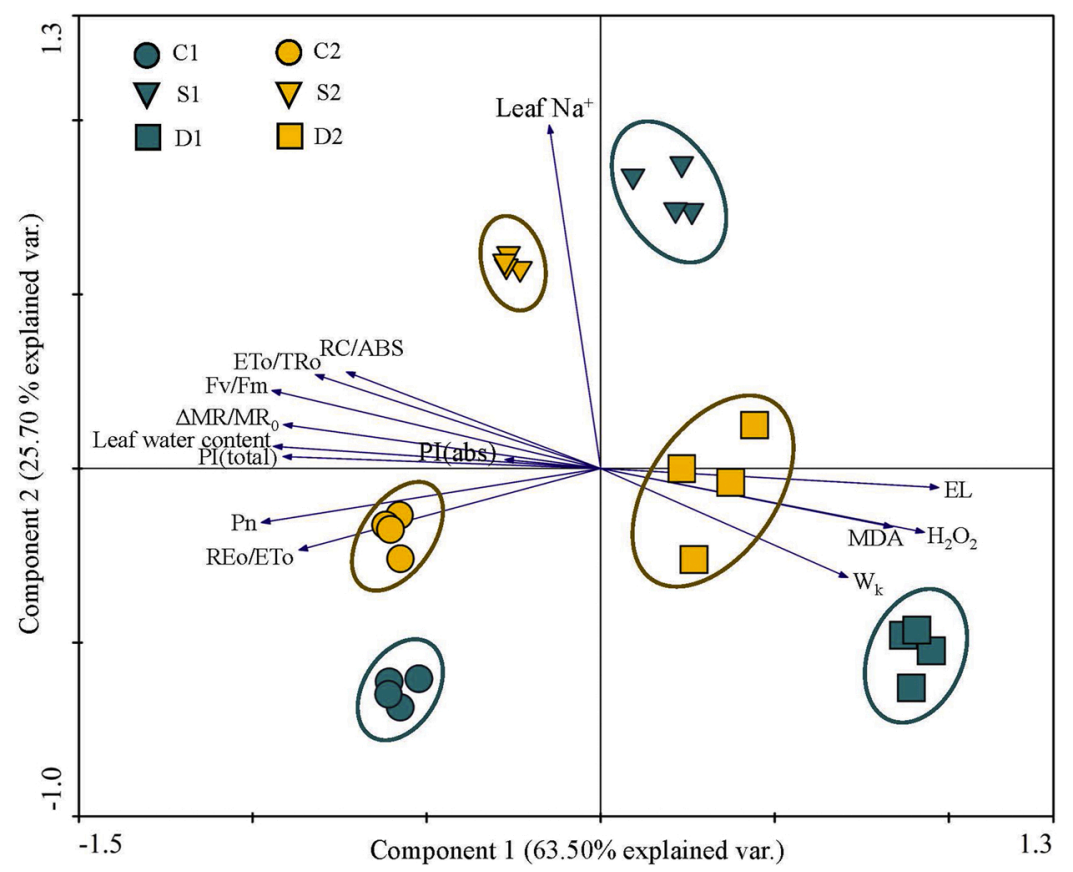

Fig. 7. Principal components analysis of the whole data involving photosynthesis, photosystem performance, oxidative stress, leaf water and $\mathrm{Na}^{+}$contents in honeysuckle after 6 days of severe and 20 days of moderate iso-osmotic salt and drought stresses.

day because of the uncompleted PSI re-reduction in $820 \mathrm{~nm}$ reflection transients (Fig. 4B). However, besides the lowered PsaA abundance and $\Delta \mathrm{MR} / \mathrm{MR}_{0}$, shortened PSI oxidation in $820 \mathrm{~nm}$ reflection transients also denoted that PSI was injured after 6 days of severe drought stress (Figs. 2A, I and 4 B). Likewise, PSI was also damaged in spite of PSII inactivation after prolonged moderate drought stress. Therefore, PSI oxidative damage could not be prevented by active photosystems interaction upon greatly elevated excitation pressure in chloroplast, although rapid PSII photoinhibition might postpone the occurrence of PSI photoinhibition. In contrast, less limitation on photosynthetic electron flow to PSI resulted from PSII stability under iso-osmotic salt stress, and then PSII and PSI connection could be sustained according to the 
normal PSI re-reduction in $820 \mathrm{~nm}$ reflection transients, but importantly, PSI never encountered big oxidative threat in absence of severe PSII photoinhibition. Notably, elevated I step and significant decrease in REo/ETo suggested that PQ re-oxidation was inhibited under iso-osmotic drought and salt stresses (Figs. 3C, D and 4). The inhibited PQ re-oxidation conformed to PSI oxidative damage under drought stress, whereas it seemed elusive under iso-osmotic salt stress given the mild PSI photoinhibition. PQ situated at cytochrome b6f complex can combine with the primary PSI acceptor, ferredoxin, for promoting PSI cyclic electron flow (Joliot and Joliot, 2006). PSI cyclic electron flow acts as a critical mechanism to protect photosynthetic apparatus in plants by discharging electron flow at the downstream of PSI and producing ATP for the repair of damaged PSII (Sun et al., 2017; Yang et al., 2018; Huang et al., 2018; Wu et al., 2019). We presumed that inhibited PQ re-oxidation might depend on rapid enhancement of PSI cyclic electron transport under salt stress. Overall, photosynthetic apparatus in honeysuckle was vulnerable to drought stress than iso-osmotic salt stress, and the differential vulnerability hardly depended on photosystems interaction.

Photosystems photoinhibition closely relates to ROS generation and oxidative stress in plants (Takahashi and Murata, 2008; Oukarroum et al., 2015). Compared with iso-osmotic salt stress, greater elevation of leaf $\mathrm{H}_{2} \mathrm{O}_{2}$ concentration and lipid peroxidation conformed to severe photosystems photoinhibition and resulted in serious oxidative destruction of leaf cell membrane integrity under iso-osmotic drought stress (Fig. 5). Furthermore, principal component analysis comprehensively showed stronger salt adaptability in honeysuckle in terms of photosynthesis, photosystems performance and oxidative stress, according to drought-induced greater cluster separation than iso-osmotic salt stress (Fig. 7). Oxidative damage is a secondary stress following osmotic pressure or ionic toxicity under salt stress (Gill and Tuteja, 2010; Hossain and Dietz, 2016). $\mathrm{Na}^{+}$is the primary toxic ion under salt stress, and $\mathrm{Na}^{+}$toxicity may not occur as rapidly as osmotic pressure but can induce worse effects on crops such as rice, lentil, sugarcane, eucalypt, wheat, but noticeably, these crops belong to salt sensitive glycophytes (Muranaka et al., 2002; Munns and Tester, 2008; Cha-um and Kirdmanee, 2010; Cha-um et al., 2010; Patade et al., 2011; Hossain et al., 2017). On the contrary, halophytes are capable to effectively maintain water homostasis and dispose of accumulated $\mathrm{Na}^{+}$under salt stress, and can better adapt to salt stress than iso-osmotic drought stress (Zhao and Harris, 1992; Zhao et al., 2003; Hassine and Lutts, 2010; Sucre and Suarez, 2011). Similarly, drought-induced tremendous leaf water loss was mitigated in honeysuckle exposed to iso-osmotic salt stress (Fig. 6B, D), which contributed to protecting against severe oxidative damage. It has been reported that succulent halophytes such as Salicornia europaea and Suaeda salsa can effectively conserve a large of amount of $\mathrm{Na}^{+}$in the vacuoles to reduce its toxicity in cytoplasm, and $\mathrm{Na}^{+}$functions as a cheap osmolyte to potentiate water absorption capacity by lowering water potential in tissues (Zhao et al., 2003; Lv et al., 2012). Accordingly, we also can suppose this positive role of leaf accumulated $\mathrm{Na}^{+}$in salt-tolerant glycophyte such as honeysuckle under salt stress.

In disagreement with our hypothesis, honeysuckle has stronger adaptability to salt stress in terms of relatively higher photosynthetic capacity, lower photosystem photoinhibition and slighter oxidative injury under salt stress than iso-osmotic drought stress. Therefore, honeysuckle resembles a halophyte rather than a salt-sensitive glycophyte in this respect, and in future, it is worthy to investigate saline water irrigation for honeysuckle because of the deficiency of fresh water in coastal zone.

\section{Authors' contributions}

Wenjun He performed the experiments and wrote the manuscript. Kun Yan designed the experiment, performed the experiments and revised the manuscript. Yue Zhang provided the plant materials and participated in plant culture. Lanxing Bian and Huimin Mei participated in the experiments. Guangxuan Han reviewed the manuscript. All authors have read the manuscript and approved the final version of the manuscript.

\section{Declaration of Competing Interest}

The authors declare that they have no conflict of interest.

\section{Acknowledgements}

This research was jointly financed by the National Key Research \& Development Program in China (2019YFD1002702), National Natural Science Foundation of China (41201292), Yantai Science and Technology Innovation Development Plan (2020MSGY065), Key Deployment Project of Chinese Academy of Sciences (KFZD-SW-113), the Strategic Priority Research Program of the Chinese Academy of Sciences (XDA23050202), and Shandong Provincial Natural Science Foundation (ZR2017QC005).

\section{References}

Allakhverdiev, S.I., Murata, N., 2008. Salt stress inhibits photosystems II and I in cyanobacteria. Photosynth. Res. 98, 529-539. https://doi.org/10.1007/s11120-0089334-x.

Amjad, M., Akhtar, S.S., Yang, A., Akhtar, J., Jacobsen, S.E., 2015. Antioxidative response of Quinoa exposed to iso-osmotic, ionic and non-ionic salt stress. J. Agron. Crop Sci. 201, 452-460. https://doi.org/10.1111/jac.12140.

Asada, K., 2006. Production and scavenging of reactive oxygen species in chloroplasts and their functions. Plant Physiol. 141, 391-396. https://doi.org/10.1104/ pp.106.082040.

Cha-um, S., Kirdmanee, C., 2010. Effects of water stress induced by sodium chloride and mannitol on proline accumulation, photosynthetic abilities and growth characters of eucalyptus (Eucalyptus camaldulensis Dehnh.). New For. 40, 349-360. https://doi. org/10.1007/s11056-010-9204-1.

Cha-um, S., Nguyen Thi Hong, N., Kirdmanee, C., 2010. Effect of mannitol- and saltinduced iso-osmotic stress on proline accumulation, photosynthetic abilities and growth characters of rice cultivars (Oryza sativa L. spp. indica). Pak. J. Bot. 42, 927-941.

Chaves, M.M., Flexas, J., Pinheiro, C., 2009. Photosynthesis under drought and salt stress: regulation mechanisms from whole plant to cell. Ann. Bot. 103, 551-560. https://doi.org/10.1093/aob/mcn125.

Dabrowski, P., Baczewska, A.H., Pawluśkiewicz, B., Paunov, M., Alexantrov, V., Goltsev, V., Kalaji, M.H., 2016. Prompt chlorophyll $a$ fluorescence as a rapid tool for diagnostic changes in PSII structure inhibited by salt stress in Perennial ryegrass. J. Photochem. Photobiol. B 157, 22-31. https://doi.org/10.1016/j. jphotobiol.2016.02.001.

Flexas, J., Medrano, H., 2002. Drought-inhibition of photosynthesis in $\mathrm{C}_{3}$ plants: stomatal and non-stomatal limitations revisited. Ann. Bot. 89, 183-189 https://doi. org/110.1093/aob/mcf027.

Gill, S.S., Tuteja, N., 2010. Reactive oxygen species and antioxidant machinery in abiotic stress tolerance in crop plants. Plant Physiol. Biochem. 48, 909-930. https://doi, org/10.1016/j.plaphy.2010.08.016.

Han, G., Sun, B., Chu, X., Xing, Q., Song, W., Xia, J., 2018. Precipitation events reduce soil respiration in a coastal wetland based on four-year continuous field measurements. Agric. For. Meteorol. 256-257, 292-303. https://doi.org/10.1016/j. agrformet.2018.03.018.

Hassine, A.B., Lutts, S., 2010. Differential responses of saltbush Atriplex halimus L. Exposed to salinity and water stress in relation to senescing hormones abscisic acid and ethylene. J. Plant Physiol. 167, 1448-1456. https://doi.org/10.1016/j. jplph.2010.05.017.

Hossain, M.S., Dietz, K.J., 2016. Tuning of redox regulatory mechanisms, reactive oxygen species and redox homeostasis under salinity stress. Front. Plant Sci. 7, 548. https://doci.org/10.3389/fpls.2016.00548.

Hossain, M.S., Alam, M.U., Rahman, A., Hasanuzzaman, M., Nahar, K., Al Mahmud, J., Fujita, M., 2017. Use of iso-osmotic solution to understand salt stress responses in lentil (Lens culinaris Medik.). S. Afr. J. Bot. 113, 346-354. https://doi.org/10.1016/j. sajb.2017.09.007.

Huang, W., Fu, P.L., Jiang, Y.J., Zhang, J.L., Zhang, S.B., Hu, H., Cao, K.F., 2013. Differences in the responses of photosystem I and photosystem II of three tree species Cleistanthus sumatranus, Celtis philippensis and Pistacia weinmannifolia exposed to a prolonged drought in a tropical limestone forest. Tree Physiol. 33, 211-220. https://doi.org/10.1093/treephys/tps132.

Huang, W., Yang, Y.J., Zhang, S.B., Liu, T., 2018. Cyclic electron flow around photosystem I promotes ATP synthesis possibly helping the rapid repair of photodamaged photosystem II at low light. Front. Plant Sci. (New Haven, CT, U. S.) 9, 239. https://doi.org/10.3389/fpls.2018.00239. 
Hussain, M.I., Lyra, D.-A., Farooq, M., Nikoloudakis, N., Khalid, N., 2015. Salt and drought stresses in safflower: a review. Agron. Sustain. Dev. 36, 1-31. https://doi. org/10.1007/s13593-015-0344-0348.

Joliot, P., Joliot, A., 2006. Cyclic electron flow in C3 plants. Biochim. Biophys. Acta 1757, 362-368. https://doi.org/10.1016/j.bbabio.2006.02.018.

Kalaji, H.M., Goltsev, V., Bosa, K., Allakhverdiev, S.I., Strasser, R.J., Govindjee, 2012. Experimental in vivo measurements of light emission in plants: a perspective dedicated to David Walker. Photosynth.Res. 114, 69-96. https://doi.org/10.1007/ s11120-012-9780-3.

Kalaji, H.M., Račková, A., Paganová, V., Swoczyna, T., Rusinowski, S., Sitko, K., 2018a. Can chlorophyll-a fluorescence parameters be used as bio-indicators to distinguish between drought and salinity stress in Tilia cordata Mill? Environ. Exp. Bot. 152, 149-157. https://doi.org/10.1016/j.envexpbot.2017.11.001.

Kalaji, H.M., Rastogi, A., Živcak, M., Brestic, M., Daszkowskagolec, A., Sitko, K., Alsharafa, K.Y., Lotfi, R., Stypinski, P., Samborska, I.A., Cetner, M.D., 2018b. Prompt chlorophyll fluorescence as a tool for crop phenotyping: an example of barley landraces exposed to various abiotic stress factors. Photosynthetica 56, 953-961. https://doi.org/10.1007/s 11099-018-0766-z.

Katuwal, K.B., Xiao, B., Jespersen, D., 2020. Physiological responses and tolerance mechanisms of seashore paspalum and centipedegrass exposed to osmotic and isoosmotic salt stresses. J. Plant Physiol. 248, 153154 https://doi.org/10.1016/j. jplph.2020.153154.

Lan, C.Y., Lin, K.H., Chen, C.L., Huang, W.D., Chen, C.C., 2020. Comparisons of chlorophyll fluorescence and physiological characteristics of wheat seedlings Influenced by iso-osmotic stresses from polyethylene glycol and sodium chloride. Agronomy (Basel, Switz.) 10, 325. https://doi.org/10.3390/agronomy10030325.

Li, P.M., Cheng, L.L., Gao, H.Y., Jiang, C.D., Peng, T., 2009a. Heterogeneous behavior of PSII in soybean (Glycine max) leaves with identical PSII photochemistry efficiency under different high temperature treatments. J. Plant Physiol. 166, 1607-1615. https://doi.org/10.1016/j.jplph.2009.04. 013.

Li, W.D., Biswas, D.K., Xu, H., Xu, C.Q., Wang, X.Z., Liu, J.K., Jiang, G.M., 2009b. Photosynthetic responses to chromosome doubling in relation to leaf anatomy in Lonicera japonica subjected to water stress. Funct. Plant Biol. 36, 783-792. htt ps://doi.org/10.1071/FP09022.

Loreto, F., Centritto, M., Chartzoulakis, K., 2003. Photosynthetic limitations in olive cultivars with different sensitivity to salt stress. Plant Cell Environ. 26, 595-601. https://doi.org/10.1046/j.1365-3040.2003.00994.x.

Lv, S.L., Jiang, P., Chen, X.Y., Fan, P.X., Wang, X.C., Li, Y.X., 2012. Multiple compartmentalization of sodium conferred salt tolerance in Salicornia europaea. Plant Physiol. Biochem. 51, 47-52. https://doi.org/10.1016/j.plaphy.2011.10.015.

Maxwell, K., Johnson, G.N., 2000. Chlorophyll fluorescence- a practical guide. J. Exp. Bot. 51, 659-668. https://doi.org/10.1093/jexbot/51.345.659.

Munns, R., 2002. Comparative physiology of salt and water stress. Plant Cell Environ. 25, 239-250. https://doi.org/10.1046/j.0016-8025.2001.00808.x.

Munns, R., Tester, M., 2008. Mechanisms of salinity tolerance. Annu. Rev. Plant Biol. 59, 651-681. https://doi.org/10.1146/annurev.arplant.59.032607.092911.

Muranaka, S., Shimizu, K., Kato, M., 2002. Ionic and osmotic effects of salinity on singleleaf photosynthesis in two wheat cultivars with different drought tolerance. Photosynthetica 40, 201-207. https://doi.org/10.1023/A:1021337522431.

Murata, N., Takahashi, S., Nishiyama, Y., Allakhverdiev, S.I., 2007. Photoinhibition of photosystem II under environmental stress. Biochim. Biophys. Acta 1767, 414-421. https://doi.org/10.1016/j.bbabio.2006.11.019.

Oukarroum, A., Bussotti, F., Goltsev, V., Kalaji, H.M., 2015. Correlation between reactive oxygen species production and photochemistry of photosystems I and II in Lemna gibba L. Plants under salt stress. Environ. Exp. Bot. 109, 80-88. https://doi.org/ 10.1016/j.envexpbot.2014.08.005.

Patade, V.Y., Bhargava, S., Suprasanna, P., 2011. Salt and drought tolerance of sugarcane under iso-osmotic salt and water stress: growth, osmolytes accumulation, and antioxidant defense. J. Plant Interact. 6, 275-282. https://doi.org/10.1080/ 17429145.2011 .557513$.

Rastogi, A., Kovar, M., HE, X., Zivcak, M., Kataria, S., Kalaji, H.M., Skalicky, M., Ibrahimova, U.F., Hussain, S., Mbarki, S., Brestic, M., 2020. JIP-test as a tool to identify salinity tolerance in sweet sorghum genotypes. Photosynthetica 58, 518-528. https://doi.org/10.32615/ps.2019.169.

Schansker, G., Srivastava, A., Govindjee, Strasser, R.J., 2003. Characterization of the 820-nm transmission signal paralleling the chlorophyll $a$ fluorescence rise (OJIP) in pea leaves. Funct. Plant Biol. 30 (7), 785-796. https://doi.org/10.1071/FP03032.

Silva, E.N., Ribeiro, R.V., Ferreira-Silva, S.L., Viégas, R.A., Silveira, J.A.G., 2010 Comparative effects of salinity and water stress on photosynthesis, water relations and growth of Jatropha curcas plants. J. Arid Environ. 74, 1130-1137. https://doi. org/10.1016/j.jaridenv.2010.05.036.

Song, J., Shi, G.W., Gao, B., Fan, H., Wang, B.S., 2011. Waterlogging and salinity effects on two Suaeda salsa populations. Physiol. Plant. 141 (4), 343-351. https://doi.org/ 10.1111/j.1399-3054. 2011.01445.x.

Sonoike, K., 2011. Photoinhibition of photosystem I. Physiol. Plant. 142, 56-64. https:// doi.org/10.1111/j.1399-3054.2010.01437.x.

Strasser, R.J., Michael, M.T., Qiang, S., Goltsev, V., 2010. Simultaneous in vivo recording of prompt and delayed fluorescence and $820 \mathrm{~nm}$ reflection changes during drying and after rehydration of the resurrection plant haberlea rhodopensis. Biochim. Biophys. Acta 1797, 122. https://doi.org/10.1016/j.bbabio.2010.03.008.
Sucre, B., Suárez, N., 2011. Effect of salinity and PEG-induced water stress on water status, gas exchange, solute accumulation, and leaf growth in Ipomoea pes-caprae. Environ. Exp. Bot. 70, 192-203. https://doi.org/10.1016/j.envexpbot.2010.09.004.

Sun, Y., Geng, Q., Du, Y., Yang, X., Zhai, H., 2017. Induction of cyclic electron flow around photosystem I during heat stress in grape leaves. Plant Sci. 256, 65-71. https://doi.org/10.1016/j.plantsci.2016.12.004.

Takahashi, S., Murata, N., 2008. How do environmental stresses accelerate photoinhibition? Trends Plant Sci. 13, 178-182. https://doi.org/10.1016/j. tplants.2008.01.005.

Turkan, I., Demiral, T., 2009. Recent developments in understanding salinity tolerance. Environ. Exp. Bot. 67, 2-9. https://doi.org/10.1016/j.envexpbot.2009.05.008.

van Zelm, E., Zhang, Y., Testerink, C., 2020. Salt tolerance mechanisms of plants. Annu. Rev. Plant Biol. 71, 403-433. https://doi.org/10.1146/annurev-arplant-050718100005.

Wu, X., Shu, S., Wang, Y., Yuan, R., Guo, S., 2019. Exogenous putrescine alleviates photoinhibition caused by salt stress through cooperation with cyclic electron flow in cucumber. Photosynth. Res. 141, 303-314. https://doi.org/10.1007/s11120-01900631-y.

Yan, K., Chen, P., Shao, H.B., Zhao, S.J., 2013. Characterization of photosynthetic electron transport chain in bioenergy crop Jerusalem artichoke (Helianthus tuberosus L.) under heat stress for sustainable cultivation. Ind. Crop. Prod. 50, 809-815. https://doi.org/10.1016/j.indcrop.2013.08.012.

Yan, K., Wu, C., Zhang, L., Chen, X., 2015a. Contrasting photosynthesis and photoinhibition in tetraploid and its autodiploid honeysuckle (Lonicera japonica Thunb.) under salt stress. Front. Plant Sci. 6, 227. https://doi.org/10.3389/ fpls.2015.00227.

Yan, K., Zhao, S., Liu, Z., Chen, X., 2015b. Salt pretreatment alleviated salt-induced photoinhibition in sweet sorghum. Theor. Exp. Plant Physiol. 27, 119-129. https:// doi.org/10.1007/s40626-015-0038-2.

Yan, K., Cui, M., Zhao, S., Chen, X., Tang, X., 2016a. Salinity stress is beneficial to the accumulation of chlorogenic acids in honeysuckle (Lonicera japonica Thunb.). Front. Plant Sci. 7, 1563. https://doi.org/10.3389/fpls.2016.01563.

Yan, K., Xu, H., Zhao, S., Shan, J., Chen, X., 2016b. Saline soil desalination by honeysuckle (Lonicera japonica Thunb.) depends on salt resistance mechanism. Ecol. Eng. 88, 226-231. https://doi.org/10.1016/j.ecoleng.2015.12.040.

Yan, K., Zhao, S., Bian, L., Chen, X., 2017. Saline stress enhanced accumulation of leaf phenolics in honeysuckle (Lonicera japonica Thunb.) without induction of oxidative stress. Plant Physiol. Biochem. 112, 326-334. https://doi.org/10.1016/j. plaphy.2017.01.020.

Yan, K., Han, G., Ren, C., Zhao, S., Wu, X., Bian, T., 2018a. Fusarium solani infection depressed photosystem performance by inducing foliage wilting in apple seedlings. Front. Plant Sci. 9, 479. https://doi.org/10.3389/fpls.2018.00479.

Yan, K., Zhao, S., Cui, M., Han, G., Wen, P., 2018b. Vulnerability of photosynthesis and photosystem I in Jerusalem artichoke (Helianthus tuberosus L.) exposed to waterlogging. Plant Physiol. Biochem. 125, 239-246. https://doi.org/10.1016/j plaphy.2018.02.017.

Yan, K., Bian, T., He, W., Han, G., Lv, M., Guo, M., Lu, M., 2018c. Root abscisic acid contributes to defending photoinibition in Jerusalem Artichoke (Helianthus tuberosus L.) under salt stress. Int. J. Mol. Sci. 19, 3934. https://doi.org/10.3390/ ijms19123934.

Yan, K., He, W., Bian, L., Zhang, Z., Tang, X., An, M., Li, L., Han, G., 2020. Salt adaptability in a halophytic soybean (Glycine soja) involves photosystems coordination. BMC Plant Biol. 20, 155. https://doi.org/10.1186/s12870-020-02371-

Yang, X.H., Liang, Z., Wen, X.G., Lu, C.M., 2008. Genetic engineering of the biosynthesis of glycinebetaine leads to increased tolerance of photosynthesis to salt stress in transgenic tobacco plants. Plant Mol. Biol. 66, 73-86. https://doi.org/10.1007/ s11103-007-9253-9.

Yang, C., Zhang, Z.S., Gao, H.Y., Fan, X.L., Liu, M.J., Li, X.D., 2014. The mechanism by which $\mathrm{NaCl}$ treatment alleviates PSI photoinhibition under chilling-light treatment. J. Photochem. Photobiol. B 140, 286-291. https://doi.org/10.1016/j. jphotobiol.2014.08.012.

Yang, X.Q., Zhang, Q.S., Zhang, D., Feng, J.X., Zhao, W., Liu, Z., Tan, Y., 2018. Interaction of high seawater temperature and light intensity on photosynthetic electron transport of eelgrass (Zostera marina L.). Plant Physiol. Biochem. 132, 453-464. https://doi.org/10.1016/j.plaphy. 2018.09.032.

Zhang, S.B., Huang, W., Zhang, J.L., Cao, K.F., 2016. Differential responses of photosystems I and II to seasonal drought in two Ficus species. Acta. O. Ecol. 73, 53-60. https://doi.org/10.1016/j.actao.2016.03.001.

Zhao, K.F., Harris, P.J.C., 1992. The effects of iso-osmotic salt and water stresses on the growth of halophytes and non-halophytes. J. Plant Physiol. 139, 761-763. https:// doi.org/10.1016/S0176-1617(11)81725-81726.

Zhao, K.F., Fan, H., Zhou, S., Song, J., 2003. Study on the salt and drought tolerance of Suaeda salsa and Kalanchoe claigremontiana under iso-osmotic salt and water stress. Plant Sci. 165, 837-844. https://doi.org/10.1016/S0168-9452(03)00282-6.

Zhu, J.K., 2002. Salt and drought stress signal transduction in plants. Annu. Rev. Plant Physiol. 53, 247-273. https://doi.org/10.1146/annurev.arplant.53.091401.143329.

Zhu, J.K., 2003. Regulation of ion homeostasis under salt stress. Curr. Opin. Plant Biol. 6, 441-445. https://doi.org/10.1016/S1369-5266(03)00085-2.

Zhu, J.K., 2016. Abiotic stress signaling and responses in plants. Cell 167, 313-324. htt ps://doi.org/10.1016/j.cell.2016.08.029. 